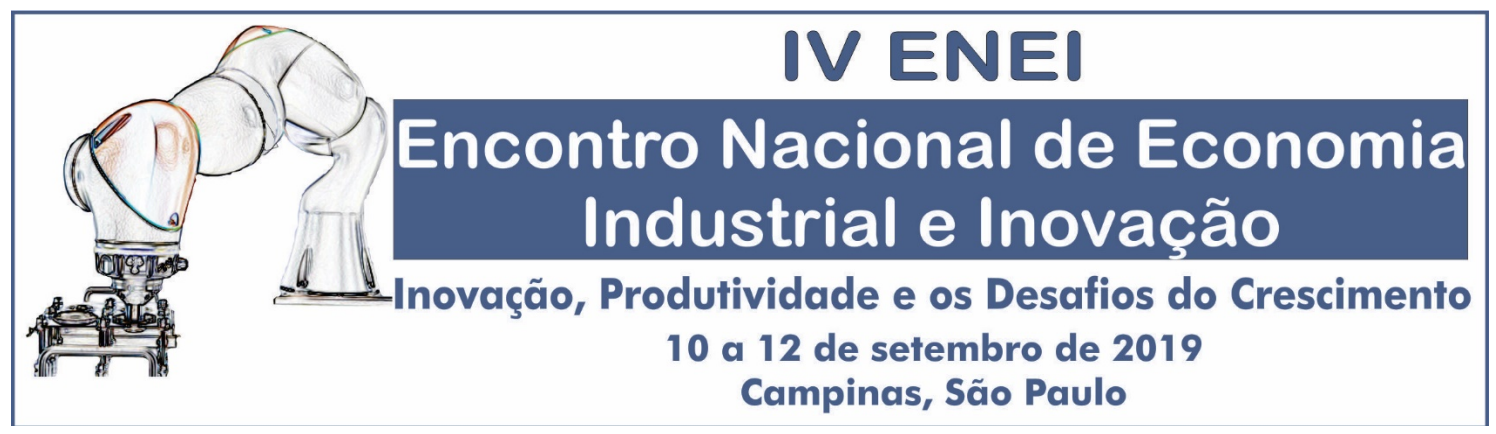

\title{
Determinantes internos e externos do crescimento e desempenho da indústria brasileira: uma análise a partir de Modelos ARDL
}

\begin{abstract}
Mestrando em Economia pelo Programa de Pós-Graduação em Economia da Universidade Federal de Uberlândia (PPGE/IERI/UFU). E-mail: rafaelmsousa1@hotmail.com.
\end{abstract}

Karina Palmieri de Almeida Mestranda em Economia pelo Programa de Pós-Graduação em Economia da Universidade Federal de Uberlândia (PPGE/IERI/UFU). E-mail: kaapalmieri@gmail.com.

\section{Resumo}

Este artigo objetiva realizar uma análise empírica dos determinantes internos e externos do crescimento (produtividade e PIB industrial), bem como apontar os principais fatores do desempenho, captados pelas exportações no Brasil, para o período de 2000 a 2018, destacando uma variável para a qualidade das exportações. A metodologia consiste em uma análise empírica realizada por meio de uma série de Modelos Auto Regressivos de Defasagens Distribuídas (ARDL) para cointegração. Os resultados encontrados sugerem que as variáveis apontadas como obstáculos ao crescimento, de fato, exerceram no longo prazo impactos negativos sobre a produtividade e o PIB industrial. Para as exportações de bens manufaturados a taxa de câmbio e a evolução dos preços foram componentes com impacto negativo para o desempenho exportador, enquanto a renda mundial como esperado foi um fator positivo, por fim a qualidade das exportações explicitou que a nossa composição da pauta exportadora é pouco propícia ao crescimento industrial.

Palavras-chave: Indústria. Desempenho. Crescimento. Modelos ARDL.

\section{Abstract}

This paper aims to perform an empirical analysis of the internal and external determinants of growth (productivity and industrial GDP), as well as to point out the main performance factors, captured by exports in Brazil, for the period from 2000 to 2018, highlighting a variable for quality of exports. The methodology consists of an empirical analysis achieved through a series of Autoregressive Distributed Lag Models (ARDL) for cointegration. The results suggest that the variables identified as obstacles to growth, in fact, had in the long run negative impacts on productivity and industrial GDP. For the exports of manufactured goods the exchange rate and the evolution of prices were components with negative impact on the export performance, while the world income as expected was a positive factor, finally the quality of exports explained that our composition of the composition of exports is less propicios to industrial growth.

Keywords: Industry. Performance. Growth. ARDL Models.

Área temática: 1. Indústria e competitividade

1.3 Crescimento, produtividade e competitividade

Códigos JEL: C01; L60; O14; O47 


\section{Introdução}

A literatura econômica embasada nos princípios de Kaldor e Thirwall estabelece a indústria como motor do crescimento econômico. Além disso, afirma que parece haver estreita relação entre o nível de renda per capita e o grau de industrialização em vários países, assim como estreita relação entre crescimento do PIB e o crescimento da indústria manufatureira, de modo que, os países que crescem com maior velocidade tendem a ser aqueles em que a participação da indústria no PIB aumenta de forma mais acentuada, i.e., típico das economias avançadas, principalmente, aqueles que delimitam ou estão mais próximo da fronteira tecnológica (THIRWALL, 2005).

Aliado a isso, a literatura aborda que o crescimento das exportações da indústria pode gerar externalidades positivas, os chamados spillovers, que impulsionam o crescimento econômico. Ou seja, ao ingressar no comércio internacional e estar exposto a um mercado mais competitivo, o país pode desenvolver economias de escala, que ofereçam uma taxa de retorno crescente, aumentando a produtividade. Portanto, a compreensão dos fatores que (des)estimulam o desempenho exportador é essencial para entender o potencial e as falhas do setor industrial de um país.

Do ponto de vista do crescimento da indústria, é importante identificar quais são os fatores que podem ser apontados como obstáculos à produtividade e o produto industrial, logo, nada melhor que a percepção do próprio setor por meio de seus agentes (pequenas, médias e grandes empresas) para apontar quais seriam esses obstáculos. Assim, variáveis referentes a custo, decisões de investimento, preços internos e externos e demanda são levantadas para verificar essa relação com o crescimento industrial.

O objetivo desse artigo é realizar uma análise empírica acerca dos determinantes de curto e longo prazo da produtividade e do PIB industrial, a partir da percepção do setor quanto aos obstáculos ao crescimento, bem como apontar os principais fatores do desempenho industrial, captados pelas exportações no Brasil para o período de 2000 a 2018, sobretudo, para averiguar os principais efeitos e quais foram os fatores (variáveis) essenciais para o desempenho industrial, destacando também uma variável para a qualidade das exportações. A metodologia aplicada consiste em uma análise empírica realizada por meio de uma série de Modelos Auto Regressivos de Defasagens Distribuídas (ARDL) para cointegração, no que tangem os indicadores de desempenho para variáveis representativas de custo, investimento, setor externo, renda e preço.

Além desta introdução, a estrutura do trabalho apresenta outras quatro seções. Na segunda seção é estruturada uma breve revisão de literatura sobre a relação das exportações com o crescimento da indústria e a importância do setor para o crescimento econômico, bem como elencar as variáveis que embasam o trabalho, agindo como fatores (internos e externos) determinantes do crescimento e do desempenho da indústria; a terceira realiza uma breve apresentação da metodologia de estimação dos modelos ARDL; a quarta discute os resultados econométricos obtidos; e, para finalizar, a quinta traz as considerações finais do trabalho.

\section{Revisão de Literatura: Determinantes do Desempenho da Indústria no Brasil}

Inicialmente, nesta seção elaborou-se uma breve revisão da literatura acerca dos fatores internos e externos que podem ser apontados como determinantes do crescimento e do desempenho industrial, assim as variáveis representam: produtividade e PIB da indústria como representações do crescimento industrial; variáveis apontadas pela percepção do setor como obstáculos ao crescimento industrial; na dimensão exportadora fatores que representam custo, investimento, renda (demanda interna e externa) e efeitos sobre a performance exportadora do setor industrial, assim como a criação de uma variável para captar a qualidade das exportações.

No final de 2012, a Agência Brasileira de Desenvolvimento Industrial (ABDI) e o Instituto de Pesquisa Econômica Aplicada (Ipea) discutiam sobre a necessidade de elaborar estudos mais aprofundados acerca da produtividade brasileira, sua evolução e seus fatores determinantes (DE NEGRI; CAVALCANTE, 2015). Isto deve-se, especialmente, ao fato de que a produtividade é um dos pilares para a retomada do ciclo de crescimento e inclusão social que marcou a economia brasileira nos primeiros anos da década de 2000, bem como para retomar o dinamismo e alavancar a economia por meio da indústria do país. 
Parte da literatura sobre determinantes e desempenho no Brasil analisa o setor industrial sob a ótica da produtividade, da competitividade, da inovação e das exportações. Segundo Messa (2015) a alta intensidade de capital na indústria possibilita um maior potencial de ganhos de produtividade por meio da absorção de tecnologia incorporada em novas máquinas e equipamentos. Além disso, o setor é visto como uma fonte de inovações relevantes para a produtividade de outras atividades econômicas. Finalmente, a indústria é tradicionalmente percebida como uma fonte de empregos de maior qualidade e menor rotatividade, o que possibilita o desenvolvimento de um capital humano específico, com um impacto positivo sobre a produtividade (MESSA, 2015).

Um dos trabalhos que relaciona os determinantes do desempenho na indústria brasileira é o de Braga (1979) que visa, por meio de uma análise econométrica de variáveis microeconômicas, desenvolver uma estrutura analítica que permita explicar as diferenças de desempenho na indústria brasileira, medido pela rentabilidade privada, tanto ao nível de gêneros de indústria como ao nível de firmas. De acordo com Braga (1979) os resultados empíricos obtidos na estimação do modelo de indústria evidenciam que as diferenças de rentabilidade observadas na indústria brasileira estão parcialmente refletindo o exercício do poder de mercado que a estrutura industrial confere. Assim, o autor aponta que apesar do elevado grau de proteção concedido à indústria no Brasil, resta ainda uma margem para a competição externa desempenhar o papel indispensável de diluir o grau de concentração doméstica e, assim, reduzir a capacidade da indústria em manter preços acima dos custos médios de longo prazo (BRAGA, 1979).

Em suas evidências empíricas, Rodrik (2006), baseando-se em evidências empíricas sobre os determinantes do crescimento sugere três premissas, a saber: I) o crescimento econômico está estreitamente correlacionado com a diversificação das atividades produtivas e não com a especialização, conforme sugerido pelos modelos clássico e neoclássico de comércio internacional; II) países que crescem mais rápido possuem setores industriais maiores como proporção da renda; III) a aceleração no ritmo de crescimento ocorre, com maior intensidade, em países que estão mudando suas estruturas produtivas em direção a setores mais complexos, particularmente a indústria de transformação e, também, ampliando o grau de sofisticação de suas exportações.

Estudos similares como de Libânio, Moro e Londe (2011) examinam a relação entre a qualidade das exportações e o crescimento econômico, a partir da classificação em categorias de intensidade tecnológica desenvolvida por Lall (2000). Sob essa perspectiva, os autores partem do pressuposto que a estrutura tecnológica, bem como o grau de intensidade tecnológica das exportações tem implicações centrais para o desenvolvimento econômico. Para tanto, Libânio, Moro e Londe (2011) tomam como ponto de partida a relação entre os padrões de especialização na economia, sobretudo, o papel da estrutura tecnológica das exportações, e o crescimento econômico em longo prazo, a partir de um arcabouço teórico Shumpeteriano e Keynesiano/Kaldoriano.

Em seus trabalhos, Kaldor (1957, 1966), já enfatizava a importância do desempenho exportador e do setor manufatureiro da indústria como estímulo ao crescimento econômico. Em contrapartida, autores cepalinos, em especial Prebisch (1962), ressaltava como o perfil exportador representava um grande obstáculo ao crescimento e desenvolvimento econômico dos países periféricos, i.e., países de pauta exportadora composta por produtos primários e importadores de produtos industrializados e de alta intensidade tecnológica (LIBÂNIO; MORO; LONDE, 2011). Diante disso, destaca-se a importância do grau de intensidade tecnológica das exportações e, consequentemente, maior valor agregado e valor total das exportações, pois acredita-se que esses produtos são, normalmente, produzidos por países mais desenvolvidos, enquanto os países em menor grau de desenvolvimento ficam restritos às exportações de produtos de baixo valor agregado e baixa intensidade tecnológica (LIBÂNIO; MORO; LONDE, 2011).

A literatura econômica embasada nos princípios de Kaldor e Thirwall estabelece a indústria como motor do crescimento econômico. Além disso, afirma que parece haver estreita relação entre o nível de renda per capita e o grau de industrialização em vários países, assim como estreita relação entre crescimento do PIB e o crescimento da indústria manufatureira, de modo que, os países que crescem com maior velocidade tendem a ser aqueles em que a participação da indústria no PIB aumenta de forma mais acentuada, i.e., típico das economias avançadas, principalmente, aqueles que delimitam ou estão mais próximo da fronteira tecnológica (THIRWALL, 2005).

Kaldor apresentou uma série de leis empíricas visando explicar as taxas de crescimento diferenciadas entre países avançados, mas que também são passíveis de aplicação aos países em desenvolvimento. Segundo Thirwall (2005) há três leis sobre as quais devemos nos concentrar, sendo elas: 
I) existe uma forte relação causal entre o crescimento da produção manufatureira e o crescimento do PIB; II) existe forte relação causal entre o crescimento da produção manufatureira e o aumento da produtividade no setor manufatureiro (esta lei também é conhecida como Lei de Verdoorn); III) existe forte relação causal positiva entre a velocidade de expansão do setor manufatureiro e o aumento da produtividade fora desse setor, sobretudo, decorrentes dos rendimentos decrescentes da agricultura e de muitas pequenas atividades de serviços que fornecem mão-de-obra ao setor industrial.

Sob essa perspectiva, segundo Kaldor o que determina o crescimento do setor manufatureiro é a demanda proveniente da agricultura, nos estágios iniciais do desenvolvimento, e o crescimento das exportações nas etapas posteriores (THIRWALL, 2005). Sendo assim, Thirwall (2005) aponta:

O rápido crescimento das exportações e da produção pode então instaurar um círculo virtuoso de crescimento, no qual o aumento acelerado das exportações leva a um crescimento rápido da produção, e o crescimento rápido da produção leva ao aumento acelerado das exportações, por meio do impacto favorável do aumento da produção na competitividade (THIRWALL, 2005, p. 44).

Há também a literatura Export-Led Growth (ELG) que enfatiza a importância das exportações, cuja hipótese postula que o aumento das exportações pode gerar externalidades positivas, os chamados spillovers, que impulsionam o crescimento econômico. Assim sendo, ao ingressar no comércio internacional e estar exposto a um mercado mais competitivo, o país pode desenvolver economias de escala, que ofereçam uma taxa de retorno crescente, aumentando a produtividade e ampliando seu acesso a novos mercados (ARAÚJO; SOARES, 2011). Ademais, Araújo e Soares (2011) apontam que todos esses fatores podem afetar outros setores da economia que não estão diretamente envolvidos com as exportações, aumentando sua produtividade e eficiência e beneficiando toda a economia.

Por meio do Gráfico 1 é possível observar a evolução das exportações de manufaturados do Brasil, no qual pode-se analisar a queda nas exportações a partir de 2006 e a sua tímida recuperação, observada a partir de 2011. A evolução da taxa de câmbio real é um dos fatores que explica a melhora no desempenho econômico do país e na performance das exportações como é exposto no Gráfico 1. Segundo os dados da CNI (2018), ainda que a moeda brasileira tenha se apreciado no período entre 2016 e 2017, ela depreciouse $30,2 \%$, entre 2011 e 2015, frente às moedas dos 11 principais parceiros comerciais do Brasil. Diante disso, a depreciação do real ajuda a explicar a melhora no desempenho exportador do país, pois, os efeitos do câmbio sobre o fluxo de comércio tendem a ser defasados (CNI, 2018).

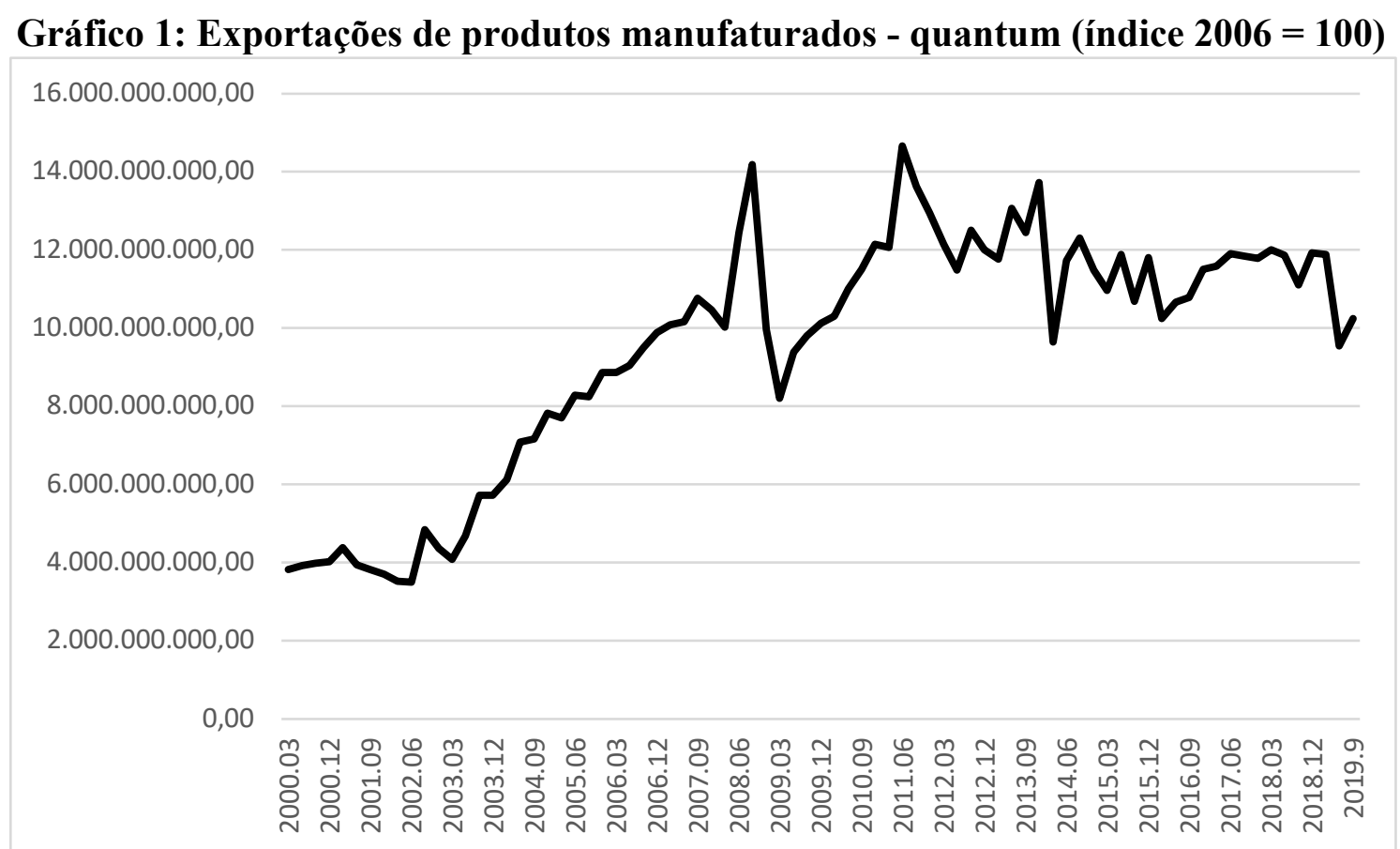

Fonte: Elaboração própria dos autores a partir dos dados do IPEA DATA/MDIC.

Por meio de seu trabalho, Libânio, Moro e Londe (2011) buscaram mostrar que a qualidade da estrutura tecnológica das exportações é importante para o crescimento econômico, examinando a hipótese 
de que uma pauta exportadora mais dinâmica está associada a um melhor desempenho econômico. Para tanto, por meio da classificação de intensidade tecnológica de Lall (2000) dividiram as exportações em dois grandes grupos, X1 que compreende produtos de menor densidade tecnológica - produtos primários, manufaturas baseadas em recursos naturais e produtos de baixa tecnologia - e o X2 que compreende produtos de alta intensidade tecnológica - constituído pelos produtos de média e alta tecnologia -. Sendo assim, os autores definiram o índice de qualidade das exportações $q_{i t}$, como:

$$
q_{i t}=\frac{X 2-X 1}{\text { Total exportado }}
$$

O índice de qualidade das exportações $q_{i t}$ varia entre - 1 e 1. Dessa forma, quanto mais próximo de 1 , melhor a qualidade das exportações do país $i$ em $t$. Por conseguinte, quanto mais próximo de -1 , menos dinâmica é a pauta.

Para efeito desta análise, utilizou-se como parâmetro o índice de qualidade das exportações $q_{i t}$ criado por Libânio, Moro e Londe (2011) visando mostrar que a qualidade da estrutura tecnológica das exportações é importante para o crescimento industrial e, consequentemente, econômico, contudo, utilizouse a classificação de intensidade tecnológica do $\mathrm{MDIC}^{1}$, a saber:

A Classificação das Exportações e Importações por Intensidade Tecnológica do MDIC é construída a partir da metodologia proposta pela OCDE. O MDIC distingue os produtos como: produtos da indústria de transformação e produtos Não Classificados na Indústria de Transformação (N. C. I. T.). Os produtos da indústria de transformação são classificados em quatro categorias, sendo elas: produtos da indústria de transformação baixa tecnologia; média-baixa tecnologia; média-alta tecnologia; e alta tecnologia.

A partir da classificação de intensidade tecnológica do MDIC, o indicador de qualidade de exportações foi adaptado da seguinte forma: X1 compreende o grupo de produtos da indústria de transformação de baixa tecnologia e média baixa-tecnologia; e o X2 compreende os produtos de média-alta tecnologia e alta tecnologia.

Para ilustrar a importância da variável da qualidade das exportações, o gráfico 2 expressa a evolução das exportações brasileiras por intensidade tecnológica em quase 20 anos.

\section{Gráfico 2: Qualidade das exportações do Brasil entre 2000 - 2019 (mensal)}

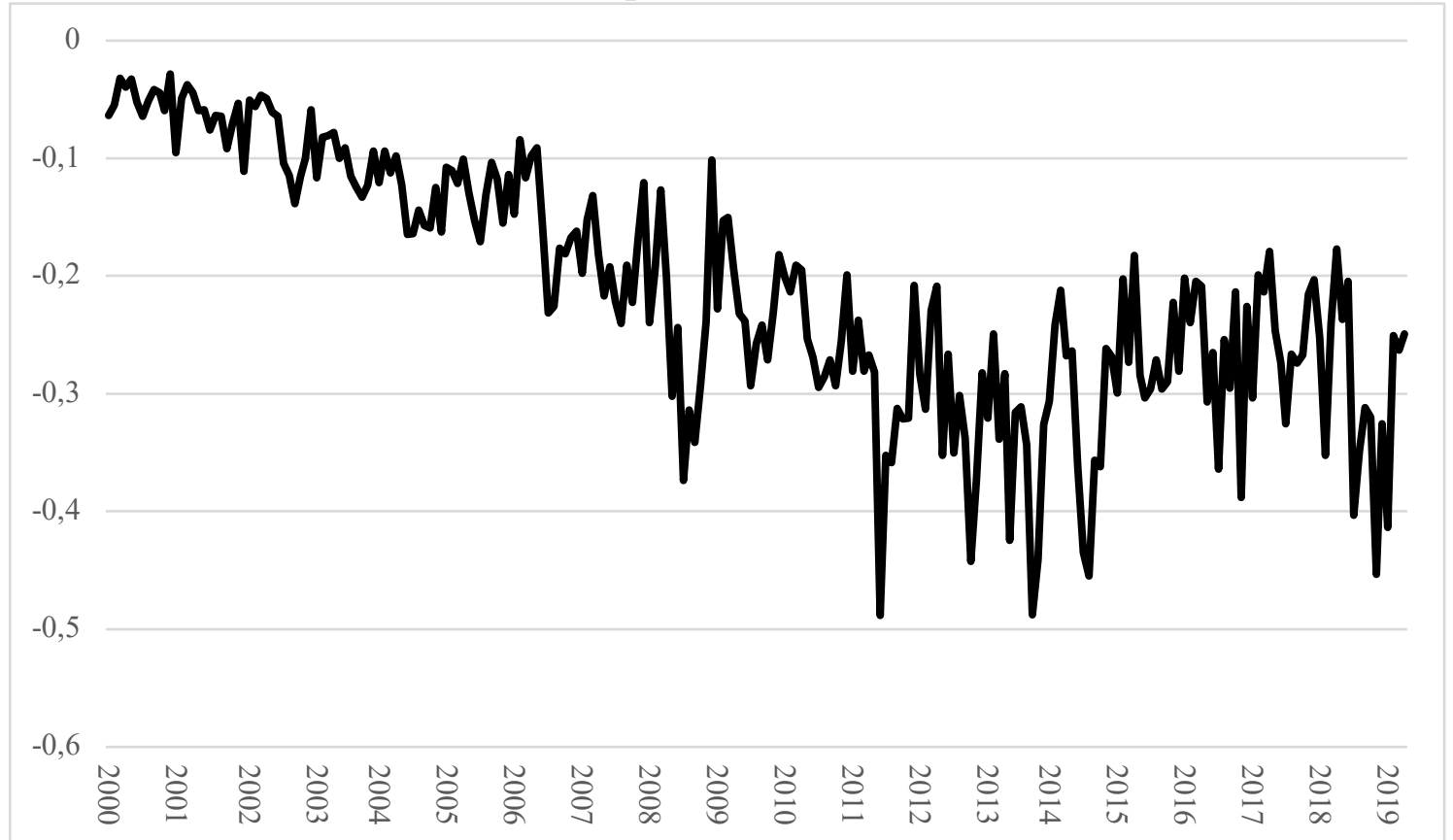

Fonte: Elaboração própria dos autores a partir dos dados do MDIC.

\footnotetext{
${ }^{1} \mathrm{Na}$ atual conjuntura Ministério da Economia, Indústria, Comércio Exterior e Serviços, antigo Ministério de Desenvolvimento, Indústria e Comércio Exterior.
} 
De acordo com os dados da Confederação Nacional da Indústria (CNI), durante o período 20062016, a perda de participação acumulada do Brasil nas exportações mundiais de manufaturados foi de $0,19 \%$, sendo que, entre 2011 e 2015, o indicador caiu 0,12\%. Em 2016, os produtos manufaturados brasileiros iniciaram um processo de recuperação da competitividade no mercado mundial, de modo que a participação do Brasil nas exportações mundiais de manufaturados cresceu de 0,59\%, em 2015, para 0,61\%, em 2016. Em contrapartida, o desempenho da participação do Brasil no valor adicionado mundial de manufaturados manteve a tendência de queda, caindo de 2,32\%, em 2015, para 2,08\%, em 2016, impactando diretamente na produtividade da indústria (CNI, 2018).

A perda de importância do Brasil na produção industrial mundial é uma tendência de longo prazo, contudo, nos últimos anos, com a crise interna política, social e econômica, que trouxe profundos desdobramentos sociais ao país, esse processo de perda de dinamismo no cenário internacional se intensificou (CNI, 2018). Nos últimos 20 anos (1997-2017), a parcela brasileira na produção industrial mundial caiu de 3,26\% para 1,98\%, não obstante, apesar da queda, o Brasil permanece no ranking entre os 10 maiores produtores de manufaturados do mundo, posicionado em nono lugar (CNI, 2018).

Como mencionado anteriormente, a crise política e econômica interna que assola o Brasil, marcada, dentre outros fatores, pela queda da demanda doméstica e a elevada ociosidade na indústria, em última instância, estimulam as empresas internas a buscarem mais intensamente o mercado externo (CNI, 2018). Sendo assim, no período mais acentuado da recessão, o mercado internacional reforçou ainda mais a sua importância para a indústria brasileira por meio da ampliação das exportações do país. Diante disso, observa-se que entre 2015 e 2016, a participação das exportações brasileiras na produção industrial cresceu de $13,8 \%$ para $15,7 \%$, como mostra o coeficiente de exportação elaborado pela CNI e pela Fundação Centro de Estudos de Comércio Exterior (FUNCEX) (CNI, 2018).

Depois de abordada a importância do desempenho exportador para o crescimento industrial e, conjuntamente, econômico, é preciso também destacar fatores internos que, por sua vez, são relevantes para a dinâmica industrial. De acordo com os dados da Sondagem Industrial de 2015, realizada trimestralmente pela CNI com pequenas, médias e grandes indústrias do Brasil, os cinco principais obstáculos que as empresas enfrentam no dia a dia dos negócios que atrapalham o crescimento industrial brasileiro são: carga tributária elevada, demanda interna insuficiente, falta ou alto custo de energia, taxa de câmbio, taxa de juros elevada (FIEPB, 2015). Isso sem considerar as adversidades do cenário político e econômico como os períodos de crise e recessão econômica que caracterizam grandes entraves ao crescimento e desenvolvimento industrial e econômico.

Por fim, as evidências empíricas para os determinantes das exportações utilizadas como referencias nesse trabalho elencam as principais variáveis com poder explicativo para verificar o desempenho exportador. O comportamento das exportações brasileiras de manufaturados foi trabalhado por Braga e Markwald (1983). Por meio de um modelo de equações simultâneas, estimado pelo método de mínimos quadrados em três estágios para dados anuais de 1959 a 1981. A quantidade de manufaturados foi medida pelo quantum de exportações da indústria de transformação. Outras variáveis foram o preço das exportações de manufaturados, medida pelo índice de preços de exportação da indústria de transformação, taxa de câmbio nominal, índice de preços domésticos, preço mundial das exportações de manufaturados, índice de incentivos fiscais à exportação, volume das importações mundiais como proxy da renda mundial e utilização da capacidade da indústria. Os resultados indicaram que a demanda mundial de exportações brasileiras é bastante sensível às variações nos preços e na renda mundial.

Os determinantes do desempenho exportador para as exportações totais do Brasil e para o quantum exportado de produtos manufaturados, semimanufaturados e básicos foi analisado por Cavalcanti e Ribeiro (1998). A série de dados compreendia observações mensais entre 1977 e 1996, e foi empregado um modelo de vetores autorregressivos e cointegração. As variáveis abordadas como importantes para a explicação da dinâmica externa foram os índices de quantum e de preços de exportação para manufaturados, básicos e semimanufaturados, índice de preço das vendas domésticas em US\$, índice de preço das importações dos países industrializados, índice das importações dos países industrializados em valor real, índice de produção física da indústria geral, PIB, índice de produto potencial e índice de utilização da capacidade produtiva. De forma geral, os resultados encontrados indicam que as exportações de produtos básicos dependem das condições de demanda do mercado internacional, em contrapartida as exportações de produtos industrializados respondem aos fatores de oferta, como taxa de rentabilidade e, provavelmente, capacidade produtiva. 
Nakabashi et al. (2008), por exemplo, verificam a relação das taxas de câmbio, de juros e do crescimento mundial sobre as exportações brasileiras e sua composição. Os resultados apontam que os setores que foram mais favorecidos pelo crescimento dos principais parceiros comerciais do Brasil e que não sofreram com variações das taxas de câmbio e juros foram os mesmos que ganharam participação no total das exportações brasileiras, ou seja, as exportações dos bens baseados em recursos naturais e em ciência.

Como observado na revisão de literatura anterior, há muitas diferenças ao avaliar o crescimento e os determinantes do desempenho do setor industrial no que tange a produtividade, a competitividade, a inovação tecnológica e as exportações. Diante disso, tendo em vista que os trabalhos que abordam temática semelhante à desta pesquisa diferem quanto ao conteúdo explorado e escolha das variáveis, discute-se sobre a necessidade de elaborar estudos mais aprofundados acerca da indústria e seus determinantes de desempenho. Sendo assim, o objetivo do trabalho consiste em realizar uma análise empírica acerca dos fatores internos e externos que atuam como determinantes de curto e longo prazo da produtividade, PIB industrial e exportações, a partir da percepção do setor quanto aos obstáculos ao crescimento, bem como apontar os principais fatores do desempenho industrial, captados pelas exportações no Brasil para o período de 2000 a 2018, visando averiguar os principais efeitos e quais foram as variáveis essenciais para o desempenho industrial, destacando também uma variável para a qualidade das exportações.

\section{Metodologia}

Este trabalho busca realizar uma análise empírica acerca do crescimento e desempenho da indústria no Brasil, em quase 20 anos, considerando fatores internos e externos como determinantes para o período de 2000 a 2018, sobretudo, para averiguar e captar o desempenho do Brasil no que tange os indicadores de desempenho para variáveis de custo, investimento, setor externo, renda e preço. Para tanto, avalia-se o comportamento e a relação a longo prazo das variáveis estimadas pelos modelos Auto Regressivos de Defasagens Distribuídas (ARDL) para cointegração, como propostos por Pesaran e Shin (1999) e Pesaran et al. (2001).

Os modelos ARDL foram escolhidos devido à sua vantagem sobre os testes de cointegração em variáveis não-estacionárias, como as desenvolvidas por Engle e Granger (1987), Phillips \& Hansen (1990) e Johansen (1991), bem como sobre modelos tradicionais de Vetores Auto Regressivos (VAR) (VIEIRA; SILVA, 2016). Além disso, os modelos ARDL aplicados à cointegração também tendem a ser mais eficientes para capturar os dados de relações de longo prazo em amostras pequenas, e pode ser aplicada em um conjunto de variáveis com diferentes ordens de integração, independentemente das variáveis serem estacionárias I (0), não estacionárias I (1) ou mesmo cointegradas (VERÍSSIMO, 2018; VIEIRA e SILVA apud PESARAN; SHIN, 1999).

Segundo Veríssimo (2018) a abordagem ARDL consiste na verificação da existência de vetores de longo prazo entre um conjunto de variáveis. Confirmada esta relação, estimam-se os coeficientes de longo e curto prazos dos modelos, bem como a velocidade de ajustamento ao equilíbrio de longo prazo (VERÍSSIMO, 2018). Para tanto, o modelo ARDL é estimado na forma de vetores de correção de erros (ARDL-ECM), que pode ser especificado da seguinte maneira:

$$
\Delta y t=\alpha_{0}+\alpha_{1 t}+\delta_{1} y_{t-1}+\delta_{2} x_{t-1}+\sum_{i=0}^{n}\left(\Phi_{1 i} \delta_{1} y_{t-i}\right) \sum_{i=0}^{n}\left(\Phi_{2 i} \delta_{1} \mathrm{x}_{t-i}\right)+\varepsilon_{t}
$$

Em que ( $\left.\mathrm{y}_{\mathrm{t}}\right)$ é a variável dependente e $\Delta$ a primeira diferença, $\left(\alpha_{0}\right)$ e $\left(\alpha_{1}\right)$ o intercepto e a tendência, (x) as variáveis independentes, $\left(\delta_{\mathrm{i}}, \mathrm{i}=1,2\right)$ representa os parâmetros de longo prazo, $\left(\Phi_{\mathrm{i}}, \mathrm{i}=1,2\right)$ os parâmetros de curto prazo e $\left(\mathscr{E}_{t}\right)$ são os distúrbios do tipo ruído branco.

Para testar a existência de associação entre a variável dependente e as variáveis explicativas, Pesaran et al. (2001) desenvolveram um teste Wald (teste-F) de limites para as relações de nível de longo prazo. Estes testes de limites de cointegração ajudam a corrigir problemas de endogeneidade e correlação das séries. Os mesmos foram baseados nas estatísticas de Wald e são válidos independente da estacionariedade da série. O teste consiste em verificar o nível de significância das defasagens das variáveis através do ECM 
ou mecanismo de correção de equilíbrio univariado. Entretanto, sob hipótese nula, as estatísticas mostramse como distribuições assintóticas e não-padrões.

Desta forma, identificada a estatística F do teste Wald define-se os limites ou valores críticos onde os regressores são todos puramente $\mathrm{I}(0)$ ou todos puramente $\mathrm{I}(1)$. A hipótese nula do teste é a inexistência de vetores de cointegração e o teste é realizado comparando a estatística $\mathrm{F}$ com os limites das bandas definidas anteriormente. Posto isto, tem-se que se a estatística $\mathrm{F}$ estiver abaixo do valor crítico, não há cointegração dos regressores, já se a estatística $\mathrm{F}$ estiver acima dos limites pode-se inferir que há cointegração entre as variáveis. Caso a estatística esteja dentro do intervalo das bandas, o teste é inconclusivo e torna-se necessário inteirar-se a respeito da ordem de integração das variáveis.

Para analisar os determinantes do crescimento e desempenho da indústria conforme proposto, a especificação de modelos ARDL aplicados à cointegração será estimada em quatro versões, conforme a seguinte especificação do modelo:

\section{Especificação do modelo:}

(VERSÃO 1): Variável Dependente: Produtividade (captar o crescimento); dados trimestrais de 2000 2019:

$$
\begin{aligned}
& \triangle \boldsymbol{P R O D}=\alpha_{0}+\alpha_{1 t}+\beta_{1}(\boldsymbol{P R O D})_{t-1}+\beta_{2}(\boldsymbol{T R I B})_{t-1}+\beta_{3}(\boldsymbol{E N E R})_{t-1}+\beta_{4}(\boldsymbol{T C R E F})_{t}+ \\
& \beta_{5}(\boldsymbol{J R})_{t-1} \beta_{6}(\boldsymbol{C A P})_{t-1}+\beta_{7}(\boldsymbol{F A T})_{t-1}+\sum_{i=0}^{n}\left(\Phi_{1 i} \delta_{1} \Delta \boldsymbol{P R O D} \boldsymbol{D}_{t-1}\right)+\sum_{i=0}^{n}\left(\Phi_{2 i} \delta_{2} \Delta \boldsymbol{T R I B} \boldsymbol{B}_{t-1}+\right. \\
& +\sum_{i=0}^{n}\left(\Phi_{2 i} \delta_{3} \Delta \boldsymbol{E} \boldsymbol{N} \boldsymbol{E} \boldsymbol{R}_{t-1}+\sum_{i=0}^{n}\left(\Phi_{2 i} \delta_{4} \Delta \boldsymbol{T C E} \boldsymbol{R}_{t-1}+\sum_{i=0}^{n}\left(\Phi_{2 i} \delta_{5} \Delta \boldsymbol{J} \boldsymbol{R}_{t-1}+\sum_{i=0}^{n}\left(\Phi_{2 i} \delta_{6} \Delta \boldsymbol{C A P} \boldsymbol{P}_{t-1}+\right.\right.\right.\right. \\
& \sum_{i=0}^{n}\left(\Phi_{2 i} \delta_{7} \Delta \boldsymbol{F} \boldsymbol{A} \boldsymbol{T}_{t-1}+\mathcal{E}_{t}\right.
\end{aligned}
$$

(VERSÃO 2): Variável Dependente: PIB Industrial (captar o crescimento); inclusão de Dummy crise para os trimestres de 2008; dados trimestrais de 2000 - 2019:

$$
\begin{aligned}
& \Delta \boldsymbol{P I B}=\alpha_{0}+\alpha_{1 t}+\beta_{1}(\boldsymbol{P I B})_{t-1}+\beta_{2}(\boldsymbol{T R I B})_{t-1}+\beta_{3}(\boldsymbol{E N E R})_{t-1}+\beta_{4}(\boldsymbol{T C R E F})_{t}+\beta_{5}(\boldsymbol{J R})_{t-1} \beta_{6}(\boldsymbol{C A P})_{t-1}+ \\
& \beta_{7}(\boldsymbol{D C R I S E})_{t-1}+\sum_{i=0}^{n}\left(\Phi_{1 i} \delta_{1} \Delta \boldsymbol{P I B} \boldsymbol{B}_{t-1}\right)+\sum_{i=0}^{n}\left(\Phi_{2 i} \delta_{2} \Delta \boldsymbol{T} \boldsymbol{R I B} \boldsymbol{B}_{t-1}++\sum_{i=0}^{n}\left(\Phi_{2 i} \delta_{3} \Delta \boldsymbol{E} \boldsymbol{N E R} \boldsymbol{R}_{t-1}+\right.\right. \\
& \sum_{i=0}^{n}\left(\Phi_{2 i} \delta_{4} \Delta \boldsymbol{T C E} \boldsymbol{R}_{t-1}+\sum_{i=0}^{n}\left(\Phi_{2 i} \delta_{5} \Delta \boldsymbol{J} \boldsymbol{R}_{t-1}+\sum_{i=0}^{n}\left(\Phi_{2 i} \delta_{6} \Delta \boldsymbol{C A P} \boldsymbol{P}_{t-1}+\sum_{i=0}^{n}\left(\Phi_{2 i} \delta_{7} \Delta \text { DCRISE } \boldsymbol{E}_{t-1}+\mathcal{E}_{t}\right.\right.\right.\right.
\end{aligned}
$$

(VERSÃO 3): Variável Dependente: Exportação de Manufaturados (proxy para desempenho da indústria); inclusão de Dummy crise para os meses de 2008; dados mensais de 2000 - 2019:

$\Delta \boldsymbol{E X P}=\alpha_{0}+\alpha_{1 t}+\beta_{1}(\boldsymbol{E X P P})_{t-1}+\beta_{2}(\boldsymbol{P R E C})_{t-1}+\beta_{3}(\boldsymbol{R W O R L D})_{t-1}+\beta_{4}(\boldsymbol{T C E R})_{t}+$

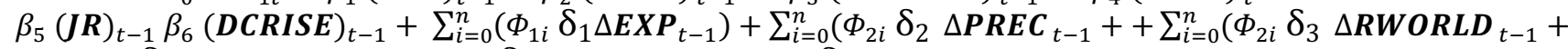
$\sum_{i=0}^{n}\left(\Phi_{2 i} \delta_{4} \Delta \boldsymbol{T C E R} \boldsymbol{R}_{t-1}+\sum_{i=0}^{n}\left(\Phi_{2 i} \delta_{5} \Delta \boldsymbol{J} \boldsymbol{R}_{t-1}+\sum_{i=0}^{n}\left(\Phi_{2 i} \delta_{6} \Delta \boldsymbol{D C R} \boldsymbol{C} \boldsymbol{S} \boldsymbol{E}_{t-1}+\boldsymbol{\varepsilon}_{t}\right.\right.\right.$

(VERSÃO 4): Variável Dependente: PIB Industrial (captar o crescimento); inclusão de Dummy crise para os trimestres de 2008; dados trimestrais de 2000 - 2019:

$\Delta \boldsymbol{P I B}=\alpha_{0}+\alpha_{1 t}+\beta_{1}(\boldsymbol{P I B})_{t-1}+\beta_{2}(\boldsymbol{P R E C})_{t-1}+\beta_{3}(\boldsymbol{R W O R L D})_{t-1}+\beta_{4}(\boldsymbol{T C E R})_{t}+$

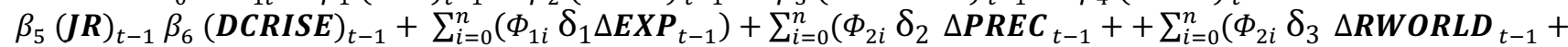
$\sum_{i=0}^{n}\left(\Phi_{2 i} \delta_{4} \Delta \boldsymbol{T C E R} \boldsymbol{R}_{t-1}+\sum_{i=0}^{n}\left(\Phi_{2 i} \delta_{5} \Delta \boldsymbol{J} \boldsymbol{R}_{t-1}+\sum_{i=0}^{n}\left(\Phi_{2 i} \delta_{6} \Delta \boldsymbol{D C R} \boldsymbol{C} \boldsymbol{S} \boldsymbol{E}_{t-1}+\boldsymbol{\varepsilon}_{\boldsymbol{t}}\right.\right.\right.$ 
As variáveis elencadas nos modelos como determinantes para o desempenho da indústria podem ser especificadas como:

\section{Quadro 1 - Variáveis selecionadas para o modelo mensais e trimestrais $(2000-2019 T 1)$}

\begin{tabular}{|c|c|c|c|}
\hline Variáveis & Definição & Fonte & Sinal esperado \\
\hline PROD & Produtividade na indústria base fixa (média $2006=100$ ) & $\mathrm{CNI}$ & - \\
\hline PIB & PIB - indústria - transformação - índice encadeado - dessaz. (média $1995=100)$ & IPEADATA & - \\
\hline EXP & Exportações - produtos manufaturados - quantum - índice (média 2006 = 100) & MDIC & - \\
\hline TRIB & Indicadores de custos industriais Índice de custo tributário (média $2006=100$ ) & $\mathrm{CNI}$ & negativo \\
\hline ENER & Indicadores de custos industriais Índice de custo com energia (média 2006 = 100) & $\mathrm{CNI}$ & negativo \\
\hline TCREF & $\begin{array}{l}\text { Taxa de câmbio - efetiva real - IPA-OG-IT - exportações - manufaturados - índice } \\
\text { (média } 2010=100)\end{array}$ & IPEADATA & negativo \\
\hline $\mathbf{J R}$ & Taxa de juros - Over / Selic & IPEADATA & negativo \\
\hline CAP & Utilização da capacidade instalada - indústria - índice (média 2010 = 100) & CNI & positivo \\
\hline FAT & Faturamento real - indústria - índice (média 2006 = 100) & IPEADATA & positivo \\
\hline QUAL & separação dos bens exportados por intensidade & CRIADA & positivo/negativo \\
\hline RWORLD & importações do mundo & WORLD BANK & positivo \\
\hline PREC & Exportações - produtos manufaturados - preços - índice (média $2006=100$ ) & IPEADATA & negativo \\
\hline DCRISE & valor 1 para todos os meses de 2008 & CRIADA & negativo \\
\hline
\end{tabular}

Fonte: Elaboração própria.

\section{Resultados}

Previamente às estimações dos modelos ARDL aplicados à cointegração, cabe avaliar a ordem de integração das variáveis utilizadas, visto que o método é adequado à estimação com variáveis com diferentes ordens de integração. Portanto, foram aplicados os testes tradicionais de raiz unitária Augmented Dickey-Fuller (ADF), Philips-Perron (PP). A Tabela 1 sintetiza os resultados destes testes, os quais indicam que algumas variáveis são consideradas I(0), enquanto outras são I(1), o que sinaliza os benefícios da utilização da metodologia proposta. 
Tabela 1 - Testes de Raiz Unitária

\begin{tabular}{c|c|c}
\hline Variáveis & ADF & PP \\
\hline PROD & -1.388225 & -1.122704 \\
PIB & -1.922857 & -1.978855 \\
EXP & -2.201318 & $-5.642692^{*}$ \\
TRIB & -2.270818 & -2.340197 \\
ENER & -0.168088 & 0.085846 \\
TCREF & -1.664457 & -1.714160 \\
JR & -2.017723 & -1.567295 \\
CAP & -0.928997 & $-3.447676^{* *}$ \\
FAT & -0.921240 & $-3.055610^{* *}$ \\
QUAL & -1.670273 & $-3.294184 * *$ \\
RWORLD & -1.181137 & -1.138231 \\
PREC & -1.341 .827 & -1.201903 \\
\hline
\end{tabular}

Fonte: Elaboração própria dos autores baseada nos resultados do Eviews 9.

Estimações com constante

$\mathrm{k}$ : número de defasagens

Valores críticos testes ADF e PP: $1 \%$ e 5\%

Valores críticos teste KPSS: $1 \%$ e $5 \%$

$(*),(* *)$ e $(* * *)$ rejeição de $\mathrm{H}_{0}$ a $1 \%, 5 \%$ e $10 \%$ de significância

ADF e PP: $\mathrm{H}_{0}$ : Tem raiz unitária

KPSS: H0: Não tem raiz unitária

Ainda, antes de se efetuar as análises de curto e longo prazo, os resultados das estimações ARDL por alguns testes de diagnóstico. Estes incluem a análise de autocorrelação dos resíduos (LM Autocorrelation Test), cuja hipótese é de não existência de autocorrelação serial. A Tabela 2, na sequência, exibe os resultados desse teste, bem como as defasagens selecionadas para cada variável dos modelos nas suas diversas especificações, sendo utilizadas quatro defasagens e o critério de informação de Akaike (AIC) como base de seleção.

Cabe destacar que todos os modelos estimados passaram nos testes de ausência de autocorrelação serial (não rejeição da hipótese nula). Também foram estimados os testes de estabilidade dos modelos CUSUM (Cumulative Sum) e CUSUMSQ (Cumulative Sum of Squares), os quais permitem avaliar a constância dos coeficientes dos modelos. A instabilidade nos parâmetros é diagnosticada se a soma cumulativa dos resíduos ultrapassa os limites da área das linhas críticas a 5\% de significância estatística, o que sinaliza a influência de quebra estrutural nas estimações. No caso das estimações dos modelos para as três versões, no qual produtividade, PIB industrial e exportações são variáveis dependentes, os testes CUSUM e CUSUMSQ apresentaram estabilidade ${ }^{2}$.

Tabela 2 - Estimativas dos modelos ARDL e Autocorrelação

\begin{tabular}{|c|c|c|c|}
\hline Modelo / Var.dependente & $\begin{array}{c}\text { Defasagens } \\
\text { selecionadas }\end{array}$ & ARDL Variáveis Significativas (Defasagens significativas) & $\begin{array}{c}\text { Teste LM } \\
\text { Autocorrelação (Prob) }\end{array}$ \\
\hline Versão 1 / Produtividade & $(3,2,1,0,1,2,3)$ & PROD (-1,-2,-3); TRIB (-2); ENER (1,-1); TCREF (1); JUR (-1); CAP (-1); FAT $(1,-2)$ & $\begin{array}{l}1.130305 \\
(0.3418)\end{array}$ \\
\hline Versão 2 / PIB Industrial & $(4,2,0,3,2,3)$ & PIB (-1); TRIB (-2); JUR (-2); CAP (1,-3), DCRISE(1) & $\begin{array}{c}2.225334 \\
(0.1341)\end{array}$ \\
\hline Versão 3 / Exp. Manufaturados & $(2,0,4,4,3)$ & JUR $(1,-1,-2,-3)$; TCREF $(1,-1,-4) ;$ RWORLD $(1,-2,-3,-4)$; PREC $(-1)$; EXP $(-1,-2)$ & $\begin{array}{c}1.106058 \\
(0.2942)\end{array}$ \\
\hline Versão 4 / PIB Industrial & $(1,0,4,2,4,0)$ & PIB (-1); TCREF (1); RWORLD $(1,-2)$; PREC $(-1,-4)$; QUAL $(1,-3,-4)$ & $\begin{array}{l}1.978918 \\
(0.1487)\end{array}$ \\
\hline
\end{tabular}

Fonte: Elaboração própria dos autores baseada nos resultados do Eviews 9.

Após certificar que as estimativas não possuíam problemas de autocorrelação e que o modelo é estável, o passo seguinte foi verificar a existência de cointegração (relação de longo prazo) entre as variáveis a partir da aplicação dos Testes de Limites (ARDL Bounds Tests), que consiste no teste de Wald

${ }^{2}$ Gráficos referentes aos testes de estabilidade dos modelos encontram-se nos anexos. 
(F-test) para avaliar a significância conjunta dos parâmetros de longo prazo dos modelos. A Tabela 3 sistematiza os resultados obtidos levando em conta os valores críticos de Pesaran et al. (2001).

Tabela 3 - Teste de cointegração (Bounds limits)

\begin{tabular}{c|c|c|c|c|c|c}
\hline \multirow{2}{*}{ Modelo / Var.dependente } & \multirow{2}{*}{ F-statistics } & \multicolumn{4}{|c|}{ Valores críticos } & \multirow{2}{*}{$\begin{array}{c}\text { Cointegração no longo } \\
\text { prazo? }\end{array}$} \\
\cline { 3 - 6 } & & $\mathbf{I}(\mathbf{0})$ BOUNDS & \multicolumn{1}{|c|}{ I(1) BOUNDS } & \\
\cline { 3 - 6 } & & $\mathbf{1 0 \%}$ & $\mathbf{5 \%}$ & $\mathbf{1 0 \%}$ & $\mathbf{5 \%}$ & SIM \\
\hline Versão 1 / Produtividade & 4,145044 & 2,12 & 2,45 & 3,23 & 3,61 & SIM \\
Versão 2 / PIB Industrial & 7,650828 & 1.81 & 2.14 & 2.93 & 3.34 & SIM \\
Versão 3 / Exp. Manufaturados & 8,322451 & 3.03 & 3.47 & 4.06 & 4.57 & SIM \\
Versão 4 / PIB Industrial & 6,385271 & 2.75 & 3.12 & 3.79 & 4.25 & \\
\hline
\end{tabular}

Fonte: Elaboração própria dos autores baseada nos resultados do Eviews 9.

Hipótese nula $\left(\mathrm{H}_{0}\right)$ : não há relação de longo prazo.

Os testes indicaram que as estatísticas-F foram maiores do que os valores críticos a $5 \%$ e $10 \%$, sinalizando a rejeição da hipótese de não cointegração. Em outras palavras, confirma-se a existência de cointegração de longo prazo entre as variáveis analisadas, indicando que as variáveis selecionadas têm papel importante para explicar na versão 1 e 2 fatores importantes ao crescimento industrial e na versão 3 aspectos relevantes para o desempenho das exportações de bens manufaturados.

Contudo, a análise do papel de cada variável explicativa em um contexto de longo prazo se torna necessária. Ademais, tais relações de longo prazo não significam a inexistência de possíveis choques de curto prazo, os quais também devem ser avaliados. Assim, na sequência, foram estimados os coeficientes de cointegração de longo prazo para todos os modelos considerados.

A Tabela 4 parte das propostas dos modelos 1 e 2, i.e., captar o crescimento da indústria a partir de sua produtividade e de seu PIB setorial, fundamentando as variáveis explicativas diante da percepção do setor aos possíveis obstáculos de crescimento da indústria, outrossim os modelo 3 e 4 pretendem verificar o principais determinantes das exportações de bens manufaturados e o impacto da qualidade das exportações no crescimento industrial, portanto, de tal maneira, contribuir para as discussões acerca do desempenho indústria.

As evidências revelam que os coeficientes significativos para o modelo 1 (a 5\% de significância) apresentaram uma relação negativa - como esperado - com a produtividade industrial, sendo eles: os custos tributários e de energia sugerindo que o aumento de $1 \%$ nos custos que incidem sobre a indústria geram uma queda em $0,41 \%$ e $0,06 \%$, respectivamente, na produtividade; a taxa de câmbio ao variar $1 \%$ impacta negativamente a produtividade em $0,08 \%$; bem como a taxa de juros ao se elevar em $1 \%$ reduz a produtividade em $0,08 \%$.

O modelo 2 foi especificado com a adição da variável do PIB industrial e de uma Dummy para captar os efeitos da crise do subprime de 2008, a finalidade ainda permanece alinhada com o modelo 1 . Ressalta-se que, mesmo após a mudança da variável dependente o sinal dos coeficientes do fator referente aos custos industriais (dessa vez tributo), da taxa de câmbio e da taxa de juros permaneceram negativos e significativos, inclusive aumentando suas magnitudes consideravelmente, de modo a confirmar que tais variáveis dentro do cenário e conjuntura econômica nacional ratificam a hipótese levantada pela sondagem industrial como obstáculos ao crescimento da indústria. Em contrapartida a proxy que permite captar a dinâmica da demanda interna para os bens industriais (utilização da capacidade produtiva) indicou efeitos positivos sobre o crescimento industrial na medida que a demanda respondia favoravelmente, logo o aumento de $1 \%$ na utilização da capacidade utilizada gera o crescimento de $1,93 \%$ no PIB industrial.

No Modelo 3, o objetivo é verificar se os efeitos de fatores externos afetaram as exportações brasileiras de bens manufaturados, variável utilizada como desempenho industrial, de forma a captar os principais determinantes do desempenho exportador da indústria. $\mathrm{O}$ resultado encontrado indica que os principais fatores de longo prazo foram a taxa de câmbio, renda mundial e a dinâmica dos preços industriais.

O conceito de taxa efetiva real de câmbio reúne, em uma só variável, três questões fundamentais para o entendimento da competitividade externa de um país: a relação entre os preços domésticos e externos, refletido na taxa de câmbio; a compreensão do que seja uma taxa efetiva, isto é, que compreenda o conjunto de países com os quais o país doméstico transaciona; e, finalmente, a relação entre inflação 
doméstica e externa, expressa no conceito "real" (NONNENBERG, 2015). Os resultados para a taxa de câmbio confirmam o que a literatura já discute como sendo desfavorável ao setor industrial, nas quatro versões apresentadas nesse trabalho a taxa de câmbio como variável de controle apresentou impacto negativo, cujo o longo prazo, na versão 3 , reflete que um aumento de um $1 \%$ da taxa de câmbio implica em redução das exportações em $0,50 \%$ salientando a relação adversa. Os preços industriais mostraram-se desfavoráveis ao desempenho exportador sugerindo que a demanda externa por bens manufaturados é sensível a altas de preços, o modelo mostra que o aumento de $1 \%$ nos preços industriais reduz em $1,76 \%$ o quantum de exportações por esses bens.

O coeficiente obtido para a renda mundial foi positivo, conforme esperado, i.e., um indício de que o setor industrial também se beneficiou do período referente a maior liquidez internacional tendo seu quantum de exportações uma tendência crescente, além disso uma depreciação momentânea a taxa de câmbio real, em 2011, contribuiu para uma leve recuperação das exportações que sofrera em períodos anteriores uma queda considerável, em resposta à crise econômica internacional, refletida por um recuo da demanda externa . Assim, o resultado aponta que um aumento de $1 \%$ na renda mundial eleva as exportações em 1,35\%, um fator externo com grau relevante para o desempenho industrial sugerindo que a indústria pode se beneficiar de bons momentos da demanda externa ainda que a predominância da pauta brasileira seja em recursos naturais.

Com relação ao modelo 4, cuja variável de interesse é a qualidade das exportações, o sinal do coeficiente da variável mostrou-se negativo, resultado que confirma o que a tendência do gráfico 2 já mostrava, ou seja, em quase 20 anos há um aprofundamento de nossa pauta exportadora de bens industriais em produtos característicos de baixa e média-baixa intensidade tecnológica com baixo valor agregado, visto que um aumento na qualidade dos nossos bens exportados significa crescimento do grupo de maior intensidade tecnológica, ou seja, o indicador mostra que a busca por maior dinamismo da nossa pauta exportadora em direção a bens de maior grau tecnológico tem potencial de gerar um impulso vultuoso sobre o crescimento industrial.

No entanto, tem-se que para a indústria brasileira a variação do indicador de qualidade das exportações leva a uma redução de $0,35^{3}$ no PIB industrial, resultado que pode ser interpretado como indício de convergia de fatores produtivos para atividades baseados em recursos naturais refletido, dessa forma, impactos negativos para o crescimento industrial. Desta maneira, pode-se confirmar, como já demostrado na literatura que uma pauta exportadora de maior grau de intensidade tecnológica funciona como um canal de crescimento industrial, bem como de fato favorece o crescimento econômico.

Tabela 4 - Coeficientes de longo prazo

\begin{tabular}{|c|c|c|c|c|c|c|c|c|c|c|c|}
\hline \multicolumn{3}{|c|}{ Versão 1 / Produtividade } & \multicolumn{3}{|c|}{ Versão 2 / PIB Industrial } & \multicolumn{3}{|c|}{ Versão 3 / Exp. Manufaturados } & \multicolumn{3}{|c|}{ Versão 4 / PIB Industrial* } \\
\hline \multicolumn{3}{|c|}{ Long Run Coefficients } & \multicolumn{3}{|c|}{ Long Run Coefficients } & \multicolumn{3}{|c|}{ Long Run Coefficients } & \multicolumn{3}{|c|}{ Long Run Coefficients } \\
\hline Variable & Coefficient & Prob. & Variable & Coefficient & Prob. & Variable & Coefficient & Prob. & Variable & Coefficient & Prob. \\
\hline TRIB & $-0,418691$ & 0.0013 & TRIB & $-0,64667$ & 0.0269 & $\mathrm{JR}$ & 0,05588 & 0.3901 & TCREF & $-0,168241$ & 0.0013 \\
\hline ENER & 0,063883 & 0.0520 & ENER & 0,006032 & 0.7708 & TCREF & -0.508874 & 0.0011 & QUAL & $-0,35046$ & 0.0326 \\
\hline TCREF & $-0,085498$ & 0.0267 & TCREF & $-0,147909$ & 0.0002 & RWORLD & 1,355986 & 0.0000 & RWORLD & 0,283795 & 0.0000 \\
\hline JR & $-0,089339$ & 0.0007 & $\mathrm{JR}$ & $-0,11929$ & 0.0024 & PREC & $-1,765481$ & 0.0000 & PREC & $-0,007055$ & 0.9149 \\
\hline CAP & $-0,695231$ & 0.0590 & CAP & 1,932933 & 0.0000 & DCRISE & $-0,014473$ & 0.7961 & DCRISE & 0,003678 & 0.8654 \\
\hline FAT & $-0,090962$ & 0.1919 & DCRISE & 0,046882 & 0.0647 & - & - & - & - & - & - \\
\hline- & - & - & - & - & - & - & - & - & - & - & - \\
\hline
\end{tabular}

Fonte: Elaboração própria dos autores baseada nos resultados do Eviews 9.

*Variável de interesse é a qualidade das exportações

O próximo passo consistiu em estimar os ajustamentos de curto prazo, via mecanismo de correção de erros (ECM) para os modelos ARDL considerados. Isso se faz necessário tendo em vista que os desequilíbrios de curto prazo podem ser vistos como um processo de ajustamento ao equilíbrio de longo prazo. Todavia, a velocidade de ajustamento a tal equilíbrio pode ser mais rápida ou mais lenta, dependendo das características das variáveis. A maior ou menor velocidade de ajustamento significa que as relações de equilíbrio entre as variáveis retornam ao estado estável de forma mais rápida ou mais lenta.

\footnotetext{
${ }^{3}$ A variável qualidade das exportações não foi expressa em logaritmo natural, logo seu resultado não corresponde a de uma elasticidade como as demais variáveis.
} 
A Tabela 5 sistematiza os resultados ECM para os modelos ARDL estimados, bem como as variáveis que foram estatisticamente significantes para a dinâmica de curto prazo. Verifica-se que os 3 sinais do Termo de Correção de Erro $\left(\mathrm{ECM}_{\mathrm{t}-1}\right)$ foram negativos e significativos em todas as estimativas. Os resultados para os modelos indicam que a velocidade de ajustamento para as versões 1 e 2 procedem em uma performance mediana, pois no modelo $1 \mathrm{em} 60 \%$ os choques são corrigidos em um trimestre, enquanto o modelo 2 responde de forma um pouco mais rápida aos choques, 66\%. De forma análoga a versão, 3 e 4 , referentes ao desempenho industrial, apresentam uma velocidade de ajustamento ainda menores, sendo que para a versão 3,55\% dos choques convergem ao equilíbrio de longo prazo em um trimestre, já para a versão 4 a reposta de convergência representa $56 \%$.

Tabela 5 - Dinâmica de curto prazo: correção de erros e variáveis significativas

\begin{tabular}{c|c|c}
\hline Modelo / Var.dependente & $\begin{array}{c}\text { ECM(-1) } \\
\text { (PROB) }\end{array}$ & Variáveis significativas \\
\hline Versão 1 / Produtividade & -0.604672 & PROD (-1); TCER(1); ENER (-1); FAT (1,-1) \\
Versão 2 / PIB Industrial & -0.660874 & \\
& $(0.0000)$ & DCRISE (1); JR (-1); CAP (1,-2) \\
Versão 3 / Exp. Manufaturados & -0.553543 & PREC (1); RWORLD (1,-1,-2,-3); EXP (-1); TCER(1,-3); JR (1,-1,-2) \\
Versão 4 / PIB Industrial & -0.563827 & \\
\hline
\end{tabular}

Fonte: Elaboração própria dos autores baseada nos resultados do Eviews 9.

A Tabela 5 também registra quais variáveis foram relevantes para explicar a dinâmica de curto prazo nos modelos estimados. Os choques de curto prazo dos valores defasados foram significativos apenas para a versão 1. A taxa de câmbio foi relevante em todos os modelos, com exceção da versão 2 . A versão 3 apresenta que todas as variáveis foram importantes no curto e longo e prazo. Na versão 4 a variável de interesse não foi significativa no curto prazo. Portanto, dentre as variáveis explicativas analisadas, nota-se que para o conjunto de modelos analisados há maior relevância dos choques de curto prazo da variável taxa de câmbio real efetiva para explicar os ajustamentos ao equilíbrio de longo prazo.

\section{Considerações Finais}

Este artigo avaliou por meio de uma análise empírica fatores internos e externos de crescimento e desempenho dos determinantes. Fatores que sugerem, em curto e longo prazo, impactos na produtividade e no PIB industrial, conforme apontado pela sondagem industrial, a partir da percepção do setor quanto aos obstáculos ao crescimento, bem como uma abordagem os principais fatores do desempenho industrial, captados pelas exportações no Brasil para o período de 2000 a 2018, sobretudo, para averiguar os principais efeitos e quais foram os fatores (variáveis) essenciais para o desempenho industrial, destacando também uma variável para a qualidade das exportações.

Os resultados confirmam que as variáveis apontadas como obstáculos ao crescimento de fato exerceram no longo prazo impactos negativos sobre a produtividade e o PIB industrial, ou seja, os fatores correspondentes à custos (tributos e energia), à dinâmica de preços externos e internos (taxa de câmbio real efetiva), a decisão de investimento (taxa de juros) apresentaram uma variação desfavorável ao crescimento industrial, em contrapartida a proxy que permite captar a dinâmica da demanda interna para os bens industriais (utilização da capacidade produtiva) indicou os efeitos positivos sobre o crescimento industrial na medida que a demanda respondia favoravelmente.

Além disso, foi percebido um impacto em menor grau da crise internacional de 2008 sobre o PIB industrial. De modo que tal influência seja melhor apreciada ao se levar em consideração seu resultado indireto para com o desempenho exportador, ou seja, na medida que a crise desacelerou a renda e a liquidez internacional e, consequentemente, a dinâmica importadora do mundo. 
Quanto ao desempenho, avaliado pelo quantum de exportações de bens manufaturados, os resultados encontrados confirmam o que a literatura já aponta para as variáveis elencadas, portanto a taxa de câmbio e a evolução dos preços de bens manufaturados para o longo prazo foram componentes com impacto negativo para o desempenho exportador, enquanto a renda mundial, como esperado, foi um fator positivo o que explica também a partir de 2008 a desaceleração das exportações de bens manufaturados. Por fim, a variável que representa a qualidade das exportações, explicitou que a nossa composição da pauta exportadora é pouco propicia ao crescimento industrial, sendo predominante em recursos naturais e bens de baixa tecnologia.

\section{Referências}

ARAUUJO, R. A.; SOARES, C. Export Led Growth' $x$ 'Growth Led Exports': What Matters for the Brazilian Growth Experience after Trade Liberalization? MPRA Paper No. 30562, posted 2. May 2011.

AVELLAR, A.P.; CARVALHO, L. (2013). Esforço inovativo e desempenho exportador: evidências para Brasil, Índia e China. Estudos Econômicos, v. 43, pp. 499-524, São Paulo.

BANCO MUNDIAL. DATABANK WORLD DEVELOPMENT INDICATORS. Disponível em: $<$ http://databank.worldbank.org $>$. Acesso em: 08 nov. 2018.

BRAGA, H. B. Determinantes do desempenho da indústria brasileira: uma investigação econométrica. R. bras. Econ. Rio de Janeiro, 1979.

BRAGA, H.; MARKWALD, R. Funções de oferta e demanda das exportações de manufaturados no Brasil. Pesquisa e Planejamento Econômico, v. 13, n. 3, p. 707-744, 1983.

CAVALCANTI, M.; RIBEIRO, F. As exportações brasileiras no período 1977/96: Desempenho e determinantes. Textos para discussão n. 545, Ipea. Rio de Janeiro, Ipea, 1998.

CARVALHO, Luciana. Ensaios sobre inovação, produtividade e exportação no Brasil. 2013. 135 f. Tese (Doutorado em Ciências Sociais Aplicadas) - Universidade Federal de Uberlândia, Uberlândia, 2013.

CNI. CONFEDERAÇÃO NACIONAL DA INDÚSTRIA. Portal da Indústria. Desempenho da indústria no mundo. Indicadores CNI, Ano 2, $N^{o} 1,2018$. Disponível: <https://bucket-gw-cni-static-cmssi.s3.amazonaws.com/media/filer_public/e0/02/e002cd55-c9db-4526-a3d1-f504c02b14f8/ desepenho_da_industria_no_mundo_julho2018.pdf $>$.

DE NEGRI, F.; CAVALCANTE, L. R (Orgs). Produtividade no Brasil: desempenho e determinantes. Vol. 2. Brasília: ABDI / IPEA, 2015.

ENGLE, R. F.; GRANGER, C. W. J. Co-integration and error correction: representation, estimation, and testing. Econométrica. p. 251-276, 1987.

FIEPB. FEDERAÇÃO DAS INDÚSTRIAS DO ESTADO DA PARAÍBA. Cinco obstáculos que atrapalham o crescimento industrial brasileiro. 2015. Disponível em: $<\mathrm{http}: / / \mathrm{www}$.fiepb.com.br/fiep/ noticias/2015/12/02/cinco_obstaculos_que_atrapalham_o_crescimento_industrial_brasileiro $>$. Acesso em: 28 out. 2018 .

IPEADATA. INSTITUTO DE PESQUISA EM ECONOMIA APLICADA. Dados macroeconômicos. Disponível em: <http://www.ipeadata.gov.br/Default.aspx>. Acesso em: 23 jan. 2018. 
NONNENBERG, Marcelo José Braga et al. Novos cálculos da taxa efetiva real de câmbio para o Brasil. 2015. Disponível em: $<\mathrm{http}: / /$ repositorio.ipea.gov.br/bitstream/11058/6215/1/nt_cc28_ cambio.pdf $>$. Acesso em: 01 jun. 2019.

JOHANSEN, S. Estimation and Hypothesis Testing of Cointegration Vectors in Gaussian Vector Autoregressive Models. Econometrica, vol. 59, pp. 1551-1580, 1991.

KALDOR, Nicholas. Causes of the Slow Rate of Economic Growth of the United Kingdom: an Inaugural Lecture. Cambridge: Cambridge University Press, 1966.

KALDOR, Nicholas. A model of economic growth. The Economic Journal, vol.67, p. 591-624, December, 1957.

LALL, Sanjaya. The technological structure and performance of developing country manufactured exports, 1985-98. Oxford Development Studies, vol. 28, no 3, 2000.

LIBÂNIO, Gilberto; MORO, Sueli; LONDE, Anna Carolina. Qualidade das exportações e crescimento econômico nos anos 2000. Anpec $-42^{\circ}$ Encontro Nacional de Economia, Rio de Janeiro, v. 42, n. 1, p.114, dez. 2011.

MDIC. MINISTÉRIO DO DESENVOLVIMENTO, INDÚSTRIA E COMÉRCIO EXTERIOR. Classificação da Secretaria de Comércio Exterior Classificação por Intensidade Tecnológica. Disponível em: <http://www.mdic.gov.br/balanca/metodologia/Nota_ISIC.pdf $>$. Acesso em: 20 mai. 2019.

MDIC. MINISTÉRIO DO DESENVOLVIMENTO, INDÚSTRIA E COMÉRCIO EXTERIOR. Estatísticas do Comércio Exterior. Disponível em: $<$ http://www.desenvolvimento.gov.br/sitio/interna/ index.php?area=5>. Acesso em: 30 jan. 2019.

MESSA, A. Determinantes da produtividade na indústria brasileira. In: DE NEGRI, F.; CAVALCANTE, L. R (Orgs). Produtividade no Brasil: desempenho e determinantes, Vol. 2. Brasília: ABDI / IPEA, 2015.

NAKABASHI, L; CRUZ, M. J. V; SCATOLIN, F. D. Efeitos do Câmbio e Juros sobre as Exportações da Indústria Brasileira. Revista Economia Contemporânea, Rio de Janeiro, v. 12, n. 3, p.433-461, set. 2008.

PESARAN, M. H.; SHIN, Y. An Autoregressive Distributed-Lag Modelling Approach to Cointegration Analysis. In: Econometrics and Economic Theory in the 20th Century: The Ragnar Frisch Centennial Symposium. Cambridge: Cambridge University Press, 1999.

PESARAN, M. H.; SHIN, Y.; SMITH, R. J. Bounds Testing Approaches to the Analysis of Level Relationships. Journal of Applied Econometrics, vol. 16, n. 3, pp. 289-326, 2001.

PHILLIPS, P. C. B.; HANSEN, B. E. Statistical Inference in Instrumental Variables Regression with I(1) Processes. The Review of Economic Studies, vol. 57, n. 1, pp. 99-125, 1999.

PHILLIPS, P. C. B. \& PERRON, P. (1988). Testing for a Unit Root in Time Series Regression. Biometrika, 75(2), p. 335-346.

RODRIK, D. Industrial Development: Stylized Facts and Policies. 2006 (In United Nations, Industrial Development for the 21st Century, U.N., New York, 2007). 
THIRLWALL, A. (2005) A Natureza do Crescimento Econômico: um referencial alternativo para compreender o desempenho das nações. Brasília: IPEA.

VERÍSSIMO, M. P. Indicadores Industriais dos Estados do Sudeste Brasileiro: Uma Análise sobre Desindustrialização a partir de Modelos ARDL. III Encontro Nacional de Economia e Inovação. UFU, Uberlândia, Minas Gerais, 2018.

VIEIRA, F. V.; SILVA, C. G. BRICS Exports Performance: an ARDL bounds testing empirical investigation. In: Anais do XLIV Encontro Nacional de Economia [Proceedings of the 44th Brazilian Economics Meeting] 101. 2016.

\section{Anexos}

Anexo 1: Teste de estabilidade CUSUM (MODELO VERSÃO 1 - Variável dependente: produtividade)

Fonte: Elaboração própria dos autores baseada nos resultados do Eviews 9.

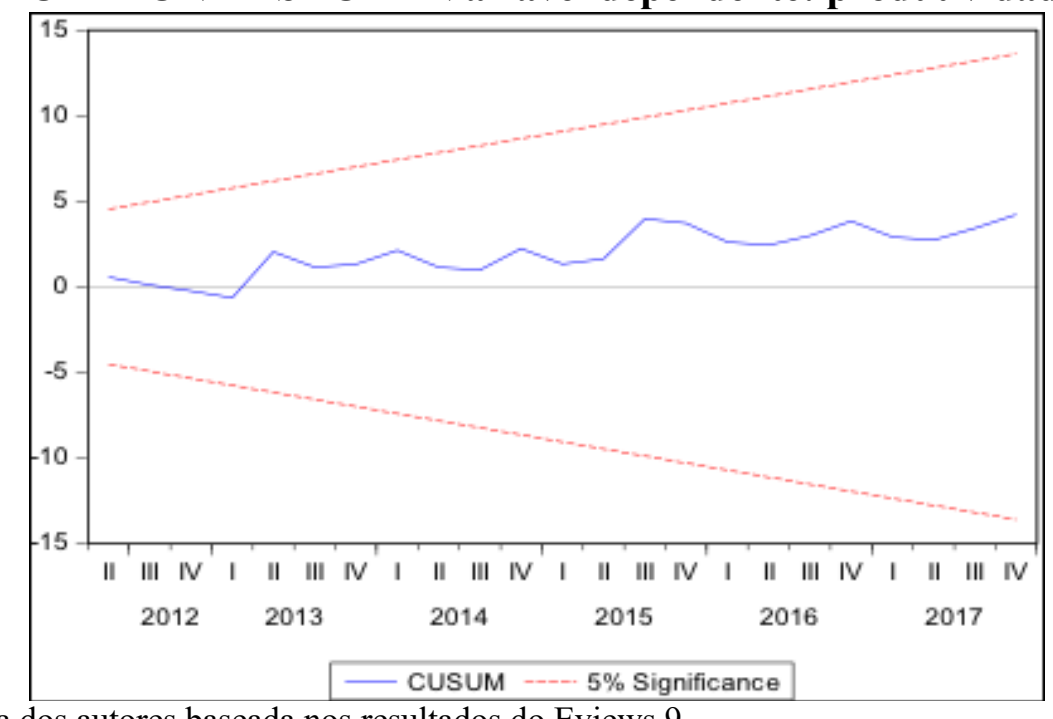

Anexo 2: Teste de estabilidade CUSUM - SQUARE (MODELO VERSÃO 1 - Variável dependente: produtividade)

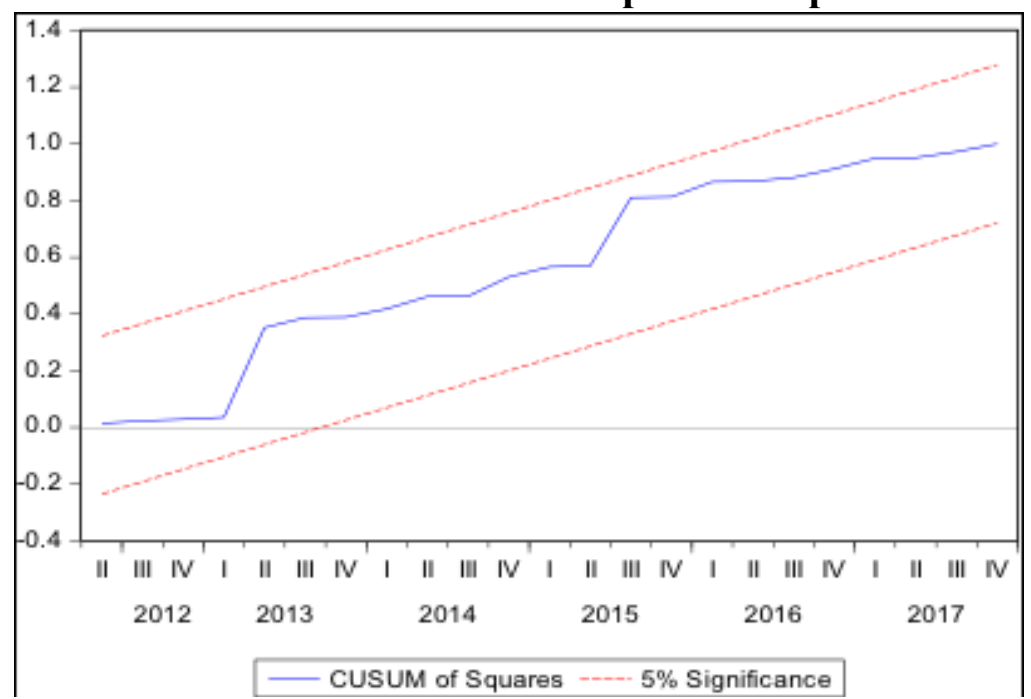

Fonte: Elaboração própria dos autores baseada nos resultados do Eviews 9. 
Anexo 3: Teste de estabilidade CUSUM

(MODELO VERSÃO 2 - Variável dependente: PIB industrial)

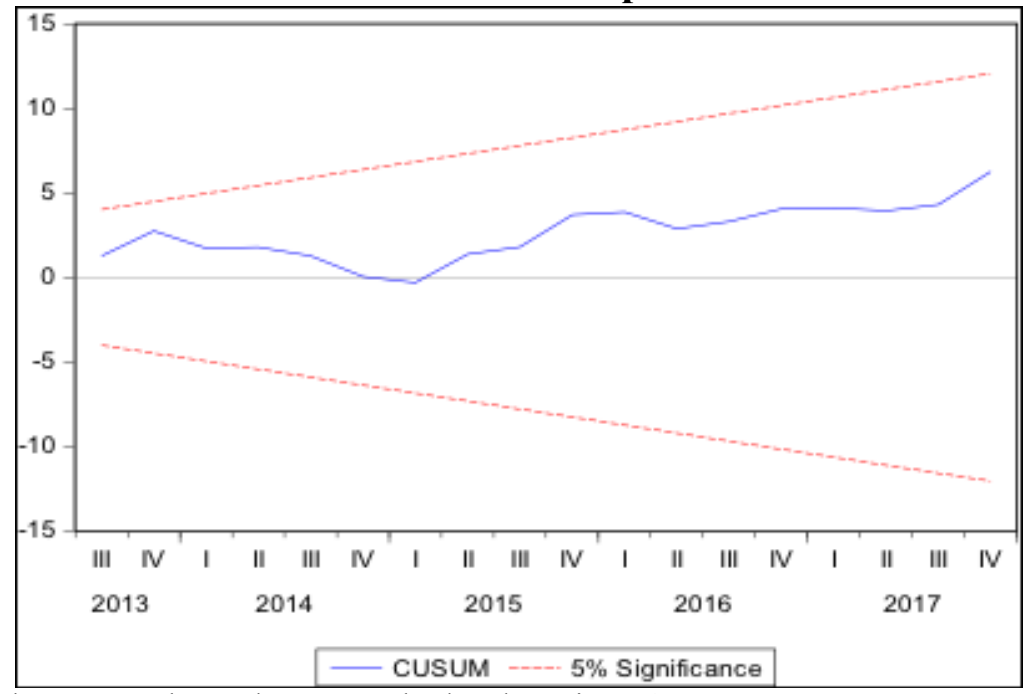

Fonte: Elaboração própria dos autores baseada nos resultados do Eviews 9.

Anexo 4: Teste de estabilidade CUSUM - SQUARE

(MODELO VERSÃO 2 - Variável dependente: PIB industrial)

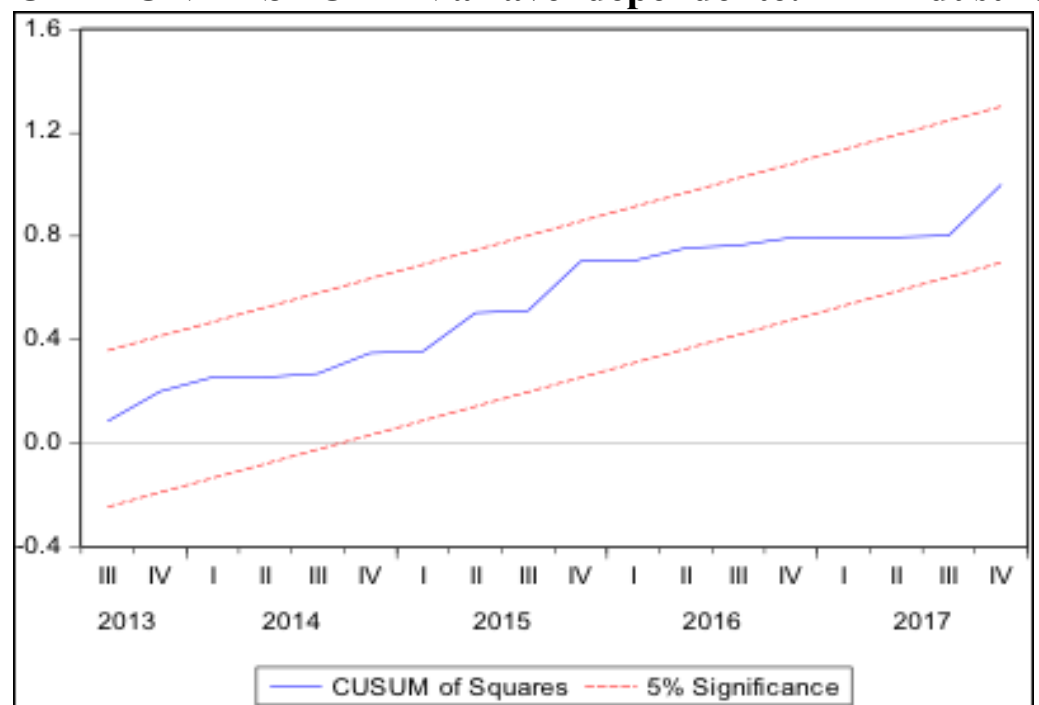

Fonte: Elaboração própria dos autores baseada nos resultados do Eviews 9.

Anexo 5: Teste de estabilidade CUSUM

(MODELO VERSÃO 3 - Variável dependente: exportações de manufaturados)

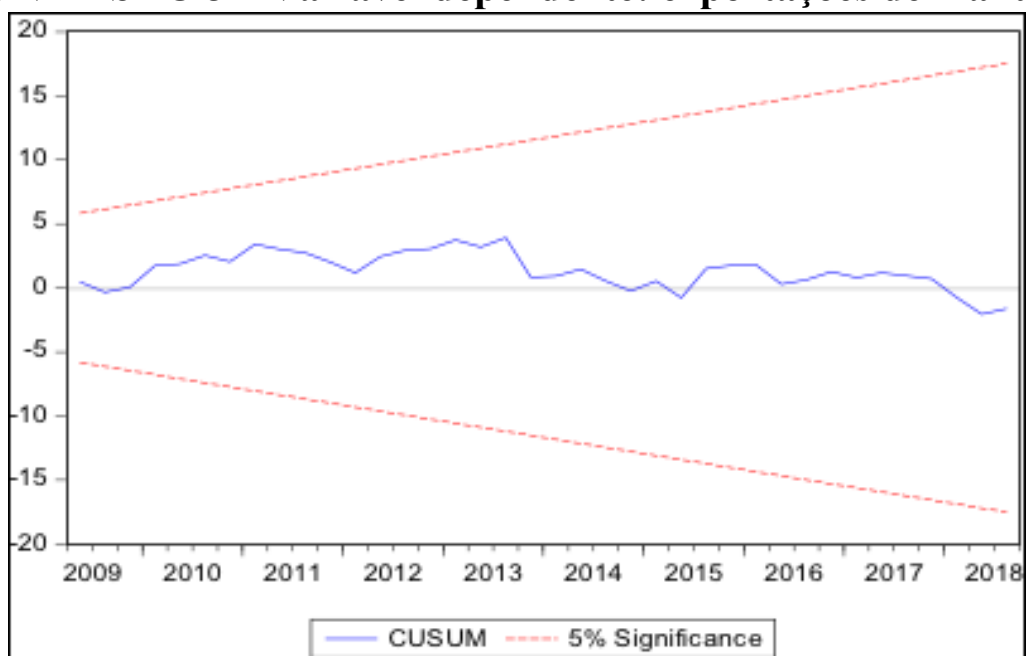

Fonte: Elaboração própria dos autores baseada nos resultados do Eviews 9. 
Anexo 6: Teste de estabilidade CUSUM - SQUARE

(MODELO VERSÃO 3 - Variável dependente: exportações de manufaturados)

Fonte: Elaboração própria dos autores baseada nos resultados do Eviews 9.

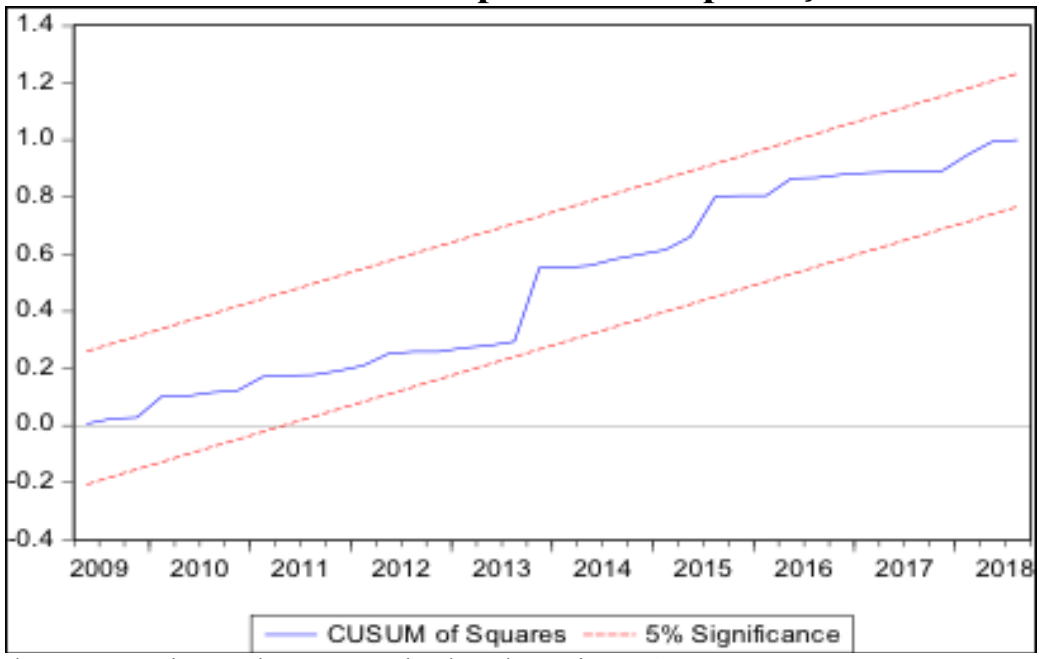

Anexo 7: Teste de estabilidade CUSUM

(MODELO VERSÃO 4 - Variável de interesse: qualidade das exportações)

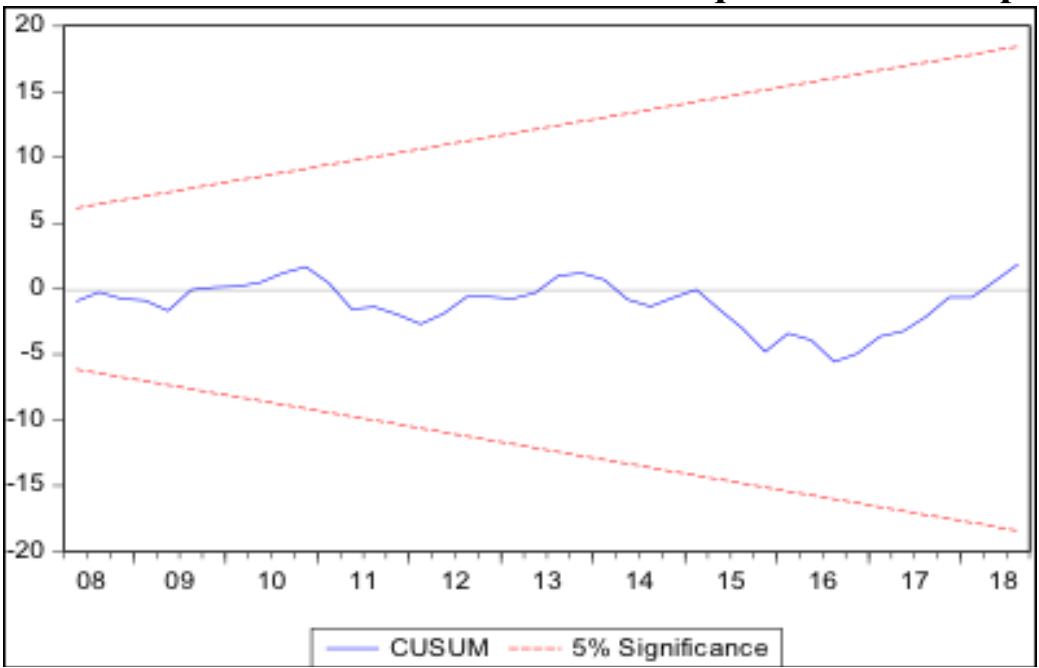

Fonte: Elaboração própria dos autores baseada nos resultados do Eviews 9.

Anexo 8: Teste de estabilidade CUSUM - SQUARE (MODELO VERSÃO 4 - Variável de interesse: qualidade das exportações)

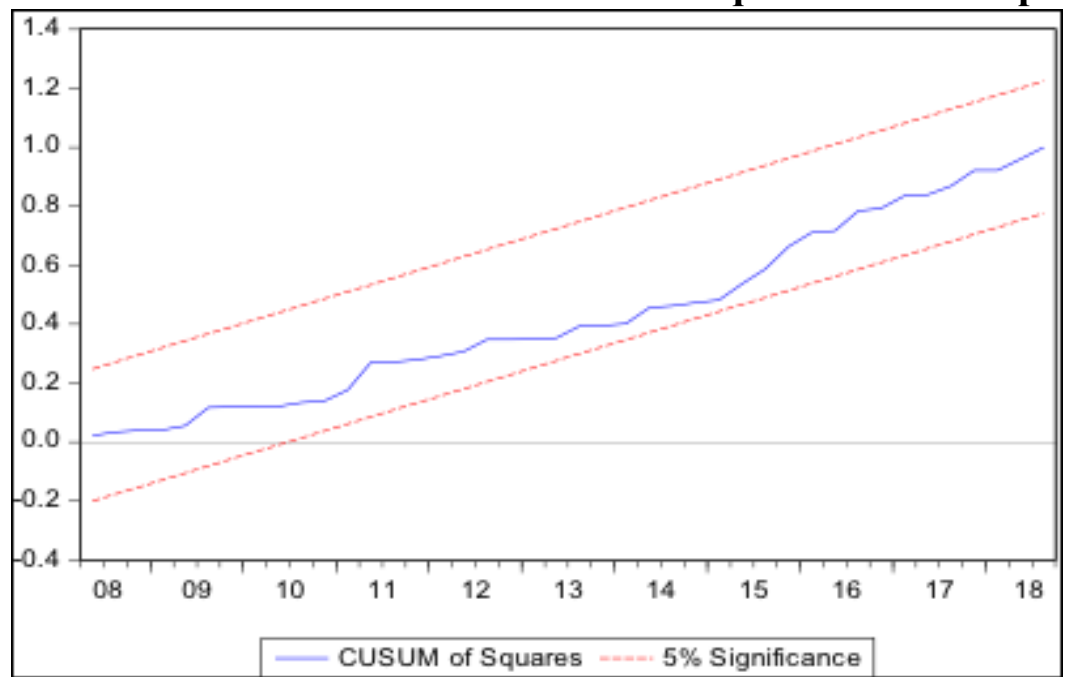

Fonte: Elaboração própria dos autores baseada nos resultados do Eviews 9. 